\title{
"Street Cred" and the Executive Woman: The Effects of Gender Differences in Social Networks on Career Advancement
}

\author{
Susan F. Cabrera \\ Melissa C. Thomas-Hunt
}

\begin{abstract}
Drawing upon Cabrera and Thomas-Hunt's (2006) theoretical framework for the advancement of executive women, we identify gender differences in social networks as an important determinant of the relative perceived credibility of men and women and the opportunities for hire and promotion available to them. A review of the existing research literature on gender and social networks is presented and several potentially fruitful avenues for future research in this area are discussed.
\end{abstract}

On the face of it, 2006 was a spectacular year for women executives. In just one year, the number of women CEOs in Fortune 100 companies increased by $100 \%$ and the number in Fortune 500 companies increased by 22\%. Underlying these startling increases were just two factors - well, to be precise just two women: Patricia Woertz of Archer Midland Daniels and Indra Nooyi of PepsiCo. With the appointment of just these two women as CEO in 2006, the representation of women at the top of the U.S. business world increased dramatically - from zero to two (0-2\%) among Fortune 100 companies and from 9 to 11 (1.8\% to 2.2\%) among Fortune 500 companies (Fortune, 2006). These discouraging statistics improve moderately when women's representation across non-CEO senior corporate positions is considered. A recent report by Catalyst (2006) indicated that in Fortune 500 companies in 2005, women held only $16.4 \%$ of corporate officer positions, $9.4 \%$ of the most powerful "clout'” positions, and even worse, made up only $6.4 \%$ of the aggregate of the five highest paid individuals within each of these companies. Further, the average growth in the percentage of women holding corporate officer positions fell to its lowest level in 10 years (Catalyst, 2006). While perhaps more extreme within the business world than in other arenas, this pattern of significant underrepresentation of women in positions of power is repeated across American society. In 2006, women made up only $15.1 \%$ of Congress (14\% of the Senate), $16 \%$ of state governors, were mayors of 12 of the top 100 U.S. cities (Rutgers University, 2006), were 21.1\% of university presidents (in 2001, the latest date where data is available) (Corrigan, 2002), and just one of the nine members of the U.S. Supreme Court was a woman, despite the fact that women make up $50.7 \%$ of the U.S. population (U.S. Census Bureau, 2006). 
Recently, we proposed a model to help explain this dearth of women in senior leadership positions (Cabrera \& Thomas-Hunt, 2006). Central to this model are the risk assessments made by employers during the hiring process. However, as illustrated in Fig. 1, before individuals are subject to these hiring risk assessments, they first must be included on the roster of candidates being considered for the position. Logically, for any given job, most individuals are not considered because, either they are not, in reality, qualified for the position, they are not perceived to be qualified, they do not know about the position or the employer does not know about them, or perhaps they do not seem to fit the usual prototype for the position. We have argued that the determination of whether individuals 'make the list'” is driven by their opportunity structure, defined as the universe of possible positions which they actually have and are perceived to be qualified for, which they know about, and to which they thus have access. This opportunity structure, in turn, is determined by factors such as individuals' previous positions, their education, their socioeconomic status, where they grew up, the information regarding employment that they have access to, as well as many others.

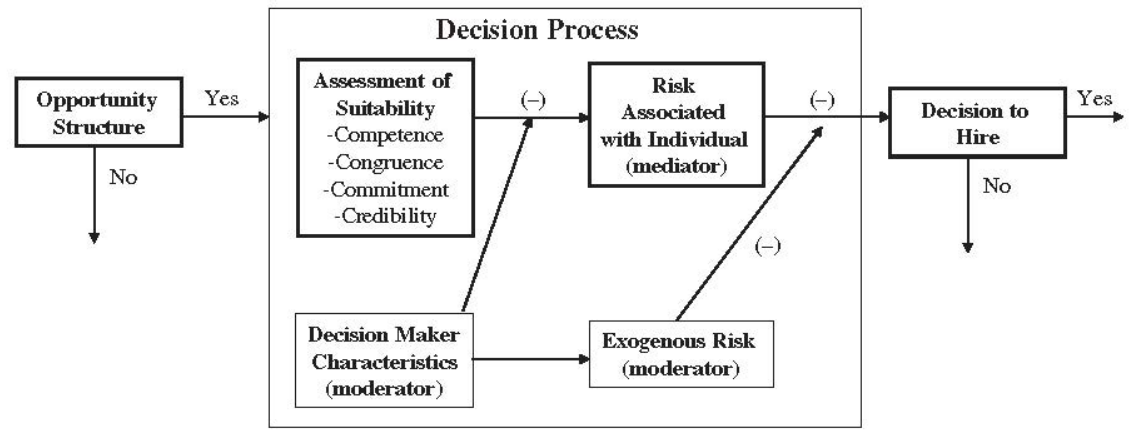

Fig. 1. An Illustration of the Risk Model of Executive Advancement. Source: Cabrera and Thomas-Hunt (2006).

According to our model, once individuals have "made the list"' and are considered for promotion or hire, employers engage in an assessment of both the individual candidate risk and the exogenous risk associated with the hiring decision (Cabrera \& Thomas-Hunt, 2006). In their assessments of candidate risk, employers evaluate the suitability of individuals on four dimensions - competence, commitment, congruence, and credibility. As candidates are evaluated as more suitable on each of these dimensions, the individual risk associated with hiring them (i.e. their candidate risk) decreases; conversely, as candidates are assessed as less suitable, their candidate risk increases. Candidate risk, in turn, mediates the decision to hire any particular individual such that the riskier the individual is perceived to be, the less likely he or she is to be hired.

In our model, we explicitly define exogenous risk as "risk in the hiring decision that is external to the particular candidate being evaluated" and suggest that it reflects the degree of exposure associated with a particular hiring decision. In assessing exogenous risk, decision makers consider factors such as the type of position and its importance to the organization, as 
well as the potential implications of the hiring decision for the prospects of the company. Assessments of exogenous risk act as a moderator on the relationship between the level of candidate risk and the decision to hire; for individuals with a given level of assessed candidate risk, if the exogenous risk is higher, they are less likely to be hired and vice versa. Put another way, if a position is critical to an organization, then to be successful in the hiring process, a candidate must be highly suitable for the job and thus, considered ' low risk." Finally, our model includes one other important element: the characteristics of the decision maker. Specifically, we have argued that the characteristics of individual decision makers, including their status, demographic attributes, gender beliefs, previous experiences, appetite for taking risk as well as other factors, will to some degree determine their particular perspective of individual candidates and situations, and thus influence their assessments of both candidate risk and exogenous risk.

Drawing on this model, we argued that with respect to each dimension of the individual risk assessment, as well as the evaluation of exogenous risk, women will tend to be at least subtly disadvantaged, relative to men (Cabrera \& Thomas-Hunt, 2006). Further, while each of these differences may be subtle and therefore, not individually concerning, it is the accumulation of small differences over the span of a career that results in dramatically fewer women in leadership positions across society. In contemplating ways in which to ameliorate the disadvantage that women face, we also suggested that female job candidates' credibility may be a key lever which can offset the lower assessments of competence, congruence, and commitment that women receive throughout the hiring process. Consequently, in this chapter we have chosen to examine the factors that enhance and thwart females' development of credibility. In particular, we focus on the impact of social networks, which may work to either support or undermine any individual's credibility. We begin by considering the different opportunity structures to which men and women have access and specifically examine how the social structural aspects of job opportunity impact the credibility which any individual job candidate brings to the hiring and promotion process.

\section{Opportunity Structure}

The accumulation of "small differences," referred to above, affects the opportunity structure within which an individual is situated. At the beginning of any individual's career, a certain set of job opportunities is available, based on the abilities and cumulative history of that person's experiences to date. As individuals progress in their careers, their opportunity structure keeps changing constantly, influenced by all prior hiring and promotion decisions and the implications of those decisions on outcomes such as the human capital the individuals develops, the relationships and networks they build, and even their attitude and feelings about work and career. As these decision processes are repeated throughout a career, individuals are funneled either toward or away from the executive suite. One particularly important determinant of any individual's opportunity structure is the social network of relationships within which he or she is 
embedded. Substantial research has shown that social networks determine access to a variety of important resources and are influential in both identification of jobs and hiring and promotion decisions (Brass, 1985; Burt, 1992, 1998; Campbell, Marsden, \& Hurlbert, 1986; Granovetter, 1974). Social networks may also provide access to high-status sponsors that can dramatically change the opportunity structure within which an individual is positioned, by providing informal information about job openings and lending legitimacy to any application for promotion or hire. As we discuss below in more detail, there are important differences in men's and women's social networks which, in turn, drive differences in the opportunity structures available to them. In order to understand how the varying opportunity structures of men and women contribute to the dearth of women at the top, and in particular, the way in which they impact the credibility of job candidates, we first explore the nature of credibility and then the convergence and divergence of men's and women's social networks and the consequences of these differences for candidate credibility and advancement.

\section{Credibility}

Numerous researchers have suggested that credibility is crucial to the advancement of women; unfortunately, they have also demonstrated that, frequently, women are not perceived as credible as their male counterparts (Burt, 1998; Carli, 2001; Hollander, 1992; Ridgeway, 2001; Valian, 1998; Yoder, 2001; Yoder, Schleicher, \& McDonald, 1998). Consistent with these findings, in our model we highlighted credibility as a particularly important determinant of women's career outcomes (Cabrera \& Thomas-Hunt, 2006). Defining credibility as " "the believability and legitimacy of an individual's credentials and future potential," we suggested that it is "both a function of perceptions of the individual's competence, congruence and commitment, and a contributing factor to those perceptions”' (Cabrera \& Thomas-Hunt, 2006). Given this influence of perceived credibility on each key dimension considered in individual risk assessments, and the fact that greater perceived credibility should also reduce the level of exogenous risk assigned to a candidate, we argued that closing the "credibility gap" between men and women is one of the most promising avenues for leveling the hiring and promotion process. We further pointed to two mechanisms which drive positive credibility assessments for women. First, existing research has shown that women can be legitimated in the hiring and promotion process through indisputable displays of competence and ability (Pugh \& Wahrman, 1983); for example, by demonstrating clear success in a position similar to the one for which the candidate is being considered (Steinpreis, Anders, \& Ritzke, 1999). In other words, for women to be successful in moving up the executive ladder, they have to be perceived as successful, which, given the biases against women often implicit in performance evaluations, often requires that women must actually be more successful than their male counterparts. A potentially more useful mechanism is suggested by a second body of research; specifically, that women may be perceived as more credible when they are “'sponsored”' by a high-status third party (Burt, 1998; DeMatteo, Dobbins, Myers, \& Facteau, 1996; Hogue, Yoder, \& Ludwig, 2002; Ibarra, 1997; 
Yoder, 2001; Yoder et al., 1998). This finding logically suggests further questions such as: Where do women find these sponsors? Do they have the same access to important high-status relationships as men? And, what are the implications of the answers to these questions on women's career outcomes? We believe that some of these questions can be answered by understanding similarities and differences in the social networks of men and women, as well as identifying the causes and outcomes of these differences. Given the important influence of social networks on the relative opportunity structures and credibility of men and women professionals, it is to this topic that we turn our attention.

\section{The Importance of Social Networks}

Implicit in the well-known quip "It's not what you know, but who you know" is the commonly held understanding that social networks matter. In the half-century since this term was coined by Barnes (1954), the study of social networks has exploded. Across a large and growing body of research, it has been shown that social networks have important and wideranging effects on many aspects of social life, including access to information, support, advice, influence, and power (Burt, 1992, 1998; Campbell et al., 1986). The nature of these social networks helps to determine outcomes as varied as the ease with which one can find a job (Granovetter, 1974) and the status of that job (Lin, Ensel, \& Vaughn, 1981), whether one attains promotions or greater influence in an organization (Brass, 1985; Burt, 1992), achieves higher income or greater mobility in the workplace (Carroll \& Teo, 1996; Podolny \& Baron, 1997), and even whether one is healthy or lives long (House, Landis, \& Umberson, 1988; Moen, DempsterMcClain, \& Williams, 1989).

It has also long been known that women do not have equal access to many of the social networks most important for attaining information, power, influence, and support within and across organizations, thus limiting women's access to the many benefits provided by them (Bartol, 1978; Kanter, 1977; Lincoln \& Miller, 1979; Miller, 1986; Miller, Labovitz, \& Fry, 1975). Despite this recognition, it is only during the last two decades that research in the area of social networks has been systematically applied to the issues of gender differentiation and inequality in our society. Traditionally, most social theories and disciplines have explained differences in the behavior, status, and social position of men and women as resulting from differences in individual-level attributes; attributes such as tastes and preferences (economists), genetics (sociobiologists), or socialization (social psychologists) (Smith-Lovin \& McPherson, 1992). Importantly, each of these interpretations suggests that men and women differ in fundamental and largely unchanging ways. In contrast, network theory provides an alternative and structural perspective in which "social processes and individual outcomes are determined by patterns of relationships among actors”' (Smith-Lovin \& McPherson, 1992, p. 223). Because men and women are embedded in different networks of relationships, they have different access to information, resources, and opportunities, in particular hiring and promotion opportunities. 
While considerable progress has been made in advancing a social network perspective of gender (Brass, 1985; Burt, 1998; Ibarra, 1992, 1997; Lincoln \& Miller, 1979; McPherson \& Smith-Lovin, 1987; McPherson, Smith-Lovin, \& Cook, 2001; Mehra, Kilduff, \& Brass, 1998; Miller, Lincoln, \& Olson, 1981; Moore, 1990; Smith-Lovin \& McPherson, 1992; van Emmerik, 2006), clearly additional work is needed. In 1993, Herminia Ibarra, one of the leading researchers in the field, proposed a conceptual framework for furthering study in this area. Focusing on personal or "ego-centric" informal interaction networks, the framework suggests a new perspective that "views network differences as reflections of purposeful strategic action within a context characterized by structural constraint”' (Ibarra, 1993, p. 57). Specifically, attributes of the organizational context such as the overall gender composition of the organization, the hierarchical distribution by gender, and turnover and mobility rates by gender both produce and interact with organizational dynamics such as the degree of gender stereotyping and the quality of gender relations to produce important differences in the networks of men and women (Ibarra, 1993). Examples of some of the mechanisms underlying this process include: lower availability of high-status, same-sex ties for women in organizations dominated by men; less perceived desirability of ties to women in organizations that rely on stereotypes of women as less competent than men; and less instrumental value of weak ties for women in organizations where women are viewed as illegitimate players.

In addition to directly affecting the personal networks of individuals, organizational factors also indirectly affect these networks by shaping the strategies available to individuals as well as the relative costs of these strategies. Importantly, Ibarra (1993) notes that although they are subject to organizational constraints, individuals are not simply passive tabula rasa upon which structure is enacted. Instead, "individuals play an active role in structuring their social networks to achieve their goals and maximize the benefits they seek" (Ibarra, 1993, p. 74); however, the strategies that individuals use are prescribed and shaped by the social context in which they are embedded. For example, in forming network ties, individuals typically demonstrate a preference for both homophily (the tendency for individuals to interact with those who have similar attributes such as race, gender, religion, or values) (McPherson et al., 2001) and for high-status network partners. In an unconstrained environment, presumably both men and women would pursue a strategy of creating homophilous and high-status networks. However, in many organizational contexts in which there are few high-status women professionals, this strategy is not available to women; in this way, the "purposeful strategic actions" of individuals are constrained by the structure of the organization (Ibarra, 1993). In other words, women, despite seeking to further their career progression by associating with highstatus individuals, are constrained in their ability to connect with those best positioned to enhance their credibility.

Ibarra (1993) argued for a multi-prong approach to future research on gender differences in personal networks, in which she first called upon researchers to move beyond simple identification of women's exclusion from informal interaction networks and toward a more 
specific understanding of the practical and theoretical ways in which men's and women's networks differ. Second, she argued that we must identify what causes network differences, focusing specifically on organizational constraints and differences in the strategies used by men and women to develop networks. Third, researchers must investigate the relationship between differences in social networks and real-world outcomes; in other words, what are the consequences of these differences? Finally, Ibarra noted the importance of conducting this type of analysis over time. While most existing research tends to be discrete in nature, taking snapshots of various networks at a given point in time, this approach is seriously limited. Duncan Watts expounded on the powerful and dynamic nature of networks in his book "Six Degrees: The Science of a Connected Age'”:

“Networks are dynamic objects not just because things happen in networked systems, but because the systems themselves are evolving and changing in time, driven by the activities or decisions of those very components. In the connected age, therefore, what happens and how it happens depend on the network. And the network in turn depends on what has happened previously. It is this view of a network - as an integral part of a continuously evolving and selfconstituting system - that is truly new about the science of networks.' (Watts, 2003, pp. 28-29)

Thus, in order to truly understand the causes, realities, and implications of gender differences in social networks, we must study them dynamically and longitudinally. While we fully endorse Ibarra's approach, we argue that given the broader context of our model (Cabrera \& Thomas-Hunt, 2006) - that is, the cross-organizational, career-spanning process through which individuals progress toward the executive suite - her approach should be extended even further to include an investigation of how the evolution of individuals' social networks are affected by societal forces such as our system of gender beliefs. Specifically, we believe that such an approach will more effectively elucidate the structural constraints which limit women's opportunities to establish credibility and their potential for attaining senior executive positions.

As will be discussed in the literature review below, substantial empirical work has been done to address the first research question posed in Ibarra's framework (i.e. identifying actual gender differences in social networks). Across a variety of contexts and using numerous different measurements, researchers have identified many of the key differences in the social networks of men and women (Brass, 1985; Burt, 1998; Ibarra, 1992, 1997; Lincoln \& Miller, 1979; McPherson \& Smith-Lovin, 1987; McPherson et al., 2001; Mehra et al., 1998; Miller et al., 1981; Moore, 1990; Smith-Lovin \& McPherson, 1992; van Emmerik, 2006). Further, some of this work has explored outcomes resulting from these differences, including impacts on influence, rate of promotion, and status in organizations (Brass, 1985; Burt, 1998; Ibarra, 1992, 1997; Lincoln \& Miller, 1979; Miller et al., 1981). To date, however, very little work has been done to systematically identify the societal and organizational factors which result in gender differences in social networks (for exceptions, see McPherson \& Smith-Lovin, 1987; South, Bonjean, Markham, \& Corder, 1982) or the different strategies used by men and women to 
develop these networks (for an exception, see Ibarra, 1992). Further, virtually no research has explored how men's and women's social networks change over time.

\section{Existing Research on Social Networks and Gender}

Over the last two decades, we have seen the development of a substantial body of research which has advanced our understanding of how the social networks of men and women differ across a number of contexts and using a variety of measurement methods. Not surprisingly, these streams of research are often overlapping and occasionally contradictory. However, in an effort to identify and describe some of the key findings, we will proceed with a discussion of the literature delineated on the basis of the specific characteristic of social networks that is being measured. This will include some of the key studies and findings around differences in network composition, as measured by homophily (Brass, 1985; Ibarra, 1992, 1997; McPherson \& Smith-Lovin, 1987; McPherson et al., 2001; Mehra et al., 1998; South et al., 1982), and range (Ibarra, 1997; Moore, 1990), and differences in relationship characteristics, as measured by tie strength (Ibarra, 1997), multiplexity (Ibarra, 1992), network centrality (Brass, 1985; Ibarra, 1992; Lincoln \& Miller, 1979; Mehra et al., 1998; Miller et al., 1981), and network constraint (Burt, 1998). In addition, throughout the discussion we will touch on what existing literature can tell us about differences in the way in which men and women translate social networks into tangible benefits (Burt, 1998; Ibarra, 1992, 1997; Lincoln \& Miller, 1979; van Emmerik, 2006) and we will identify instances where existing research investigates or informs either the societal or organizational factors influencing gender differences in social networks or the outcomes resulting from these differences.

\section{Homophily}

Homophily, the tendency for individuals to interact with those who have similar attributes such as race, gender, religion, or values, is one of the most common measurements of network composition and has been a particular focus of attention for gender researchers. Several early studies demonstrated the pervasiveness of gender homophily in the workplace and its harmful impact on women. Specifically, in his study of non-supervisory employees of a newspaper publishing company, Brass found that while women were slightly more central within the organization overall, two sex-segregated networks were underlying this pattern (Brass, 1985). As a result of women's low degree of interaction with men, they were excluded from the entirely male "dominant coalition"' in the organization, and thus were less influential and less likely to be promoted than men. South and colleagues, in their study of female employees of a large federal bureaucracy, found a similar association between gender homophily and negative outcomes for women; as the number of women in the organization increased, the degree of homophily increased, resulting in less interaction between women and men and less social support provided to women by men (South et al., 1982). 
While the prior studies tended to focus on individual preferences for homophily (the " "preference perspective'), a number of other studies argue that it is the availability of same-sex contacts within a given social context or organization that largely influences gender differences in network homophily (the "structural perspective"). This structural perspective was popularized by Blau, who argued that "social associations depend on opportunities for social contact"' (Blau, 1977, p. 281). In other words, the network relationships that individuals choose to form are highly constrained by the composition and dynamics of the social context in which they are embedded. Consistent with this argument, a number of studies have shown that the availability of same-sex contacts, as well as the relative status of those contacts, affects the degree of homophily of individuals' social networks. In their 1987 study of homophily in voluntary organizations, McPherson and Smith-Lovin coined the terms "choice homophily" which is the type of homophily produced by individual choices and "induced homophily" which is the result of constraints imposed by group composition (McPherson \& Smith-Lovin, 1987). Not surprisingly, they found evidence of both types; however, for age, sex, and occupation attributes, induced homophily was the more powerful factor.

Several years later, Ibarra extended this research in a study of professional and semiprofessional employees of a regional advertising firm by empirically testing the competing hypotheses from the preference and structural perspectives to determine whether the degree of network homophily is driven by individual preferences for same-sex ties or by the structurally determined opportunity for forming homophilous ties (Ibarra, 1992). Further, the paper offered a theoretical argument integrating the two perspectives. Although individuals in general have a tendency toward gender homophily, since women in work organizations are often at a disadvantage to men with respect to status and access to resources, women may rationally perceive interaction with men as a more effective strategy to achieve influence, status and power. As a result, "preferences for homophily and status will tend to coincide for men and exist in competition for women', (Ibarra, 1992, p. 425) and therefore, women will pursue a differentiated strategy to obtain friendship, social support, and emotional mentoring from women while attempting to access more instrumental information, advice and influence through relationships with men. To test this proposition, Ibarra distinguished between "instrumental networks" which are comprised of relationships that " arise in the course of work role performance and involve the exchange of job-related resources, including information, expertise, professional advice, political access, and material resources"' and "expressive networks" which are comprised of relationships that "involve the exchange of friendship and social support and are characterized by higher levels of closeness and trust than those that are exclusively instrumental" (Ibarra, 1993, p. 59). As predicted, the study's findings supported Ibarra's interpretation that men and women pursue different network strategies; men demonstrated a high degree of homophily across all networks, while women had more heterophilous ties within their instrumental networks and more homophilous ties in their expressive networks (Ibarra, 1992). 
Ibarra further extended this research by linking homophily to performance outcomes for men and women in a 1997 study of mid-level managers in four Fortune 500 companies (Ibarra, 1997). In a pattern suggestive of induced homophily, men had more homophilous information and career contacts than women. However, high-performing women had more homophilous information and career ties than non-high-performing women and in fact, not a single non-highperforming woman reported seeking out instrumental ties with other women. While this finding is contrary to previous arguments that homophily is detrimental to women (Brass, 1985; South et al., 1982), Ibarra argued that it is evidence of choice homophily on the part of high-performing women and may demonstrate the important role that same-sex relationships can have in providing support and advice, including on topics such as how to attract organizational sponsors and enhance one’s perceived credibility (Ibarra, 1997; Kram, 1988).

Mostly recently, Mehra and colleagues demonstrated evidence of homophily in friendship networks, in this instance in the context of a nationally ranked MBA program (Mehra et al., 1998). While prior studies were primarily conducted in hierarchical organizations, this study found that friendship networks within the context of a "de-layered"' environment still showed a strong pattern of gender homophily. Interestingly, for women, this homophily may have been largely induced, as the lower status of women rendered them less attractive as network partners. The findings were supportive of this explanation, indicating that "the marginalization of women resulted more from exclusionary pressures than from their preferences for women friends"' (Mehra et al., 1998, p. 447).

In summary, homophily has been shown to be both an important dimension upon which the social networks of men and women differ and a noteworthy determinant of women's perceived credibility and career advancement. While both choice and induced homophily were observed, induced homophily appears to play a greater role within work environments and instrumental networks. Further, within the workplace, women tend to have less homophilous networks than men because they employ a differentiated strategy, seeking out heterophilous instrumental ties and homophilous expressive ties. Finally, homophily has been shown to have both detrimental and beneficial effects on women's careers. On the one hand, greater homophily may limit women's access to the halls of power in organizations, in particular, making it less likely that they will receive the support of high-status organizational sponsors which are crucial to closing the gender credibility gap. In addition, homophilous networks are likely to contribute to men and women having access to different types of information about jobs and promotions, with women potentially being less aware of high-status opportunities than men. On the other hand, relationships with other women in similar situations may provide valuable and needed social support and advice.

\section{Tie Strength}

Tie strength indicates " the amount of time, the emotional intensity, the intimacy (mutual confiding), and reciprocal services which characterize the tie’' (Granovetter, 1973, p. 1361). As 
such, strong ties are generally associated with being closer, more stable and reciprocal, and characterized by more frequent interaction, while weak ties are characterized by relationships that are more distant in nature, involve infrequent communication and less emotional investment (Ibarra, 1993).

In a landmark work, Granovetter demonstrated that weak ties, as important avenues for accessing non-redundant information, ideas, and opportunities, can be more valuable than strong ties for instrumental purposes such as finding a job (Granovetter, 1973). Inversely, strong ties, which tend to be more homogeneous and therefore more redundant in information, may be less instrumentally productive, but provide other types of benefits such as greater opportunities for influence and persuasion, a higher likelihood of help in a crisis (Granovetter, 1982; Krackhardt, 1992), and a greater degree of sponsorship and legitimacy within and across organizations (Burt, 1992, 1998). Recognizing the different benefits of strong and weak ties, several researchers have argued that the most effective networks will be relatively well balanced between the two (Brass, 1984; Granovetter, 1982).

However, the relative value of strong and weak ties may differ for women, in particular for instrumental purposes. In her 1997 study of managerial networks, Ibarra found that highperforming women relied more heavily on strong ties than non-high-performing women and all men. While the traditional notion that women prefer close, intimate relationships might have explained the difference with men, it did not explain the difference between high and non-highperforming women. Thus, Ibarra proposed the alternative explanation that strong ties are more instrumentally effective for women than weak ties because they "help women to counteract the effect of bias, gender-typed expectations, and contested legitimacy”' (Ibarra, 1997, p. 99). In a similar vein, Burt reported that women who relied on a high-status organizational sponsor to form their social networks were promoted earlier than women who directly built their own networks (Burt, 1998). He attributed this finding to women's lack of legitimacy within the focal organization of the study.

In summary, strong ties may be particularly crucial for women to establish credibility, as it is the partners in these intimate, intense, and reciprocal relationships who are most likely to act as organizational sponsors and advocate for their career advancement. It is equally important, however, that women form strong ties with the "right" people; specifically, with highstatus, typically male individuals. Unfortunately, given individuals’ preference for homophily, it may be difficult for women to form strong ties with high-status men. Exacerbating this difficulty even more may be prescriptive social norms which define and limit the level of closeness which is appropriate in a male-female work relationship. Further, women's necessary focus on developing strong ties in order to successfully recruit legitimating organizational sponsors may limit their access to the same level of information about opportunities for development, promotion, or hire which men have as a result of maintaining broader networks of weak ties. 


\section{Multiplexity}

A network concept closely related to tie strength, multiplexity is the number of relationship dimensions associated with each individual tie. For example, a tie that is characterized by a workplace relationship, a friendship relationship, and an extended family relationship would be considered one of high multiplexity, while a tie that is characterized by only a workplace relationship would not. Ties that are higher in multiplexity are generally considered to be stronger, closer, more stable, and more likely to be reciprocal (Granovetter, 1973; Ibarra, 1992).

In her 1992 paper, Ibarra argued that one potential but perhaps less obvious implication of the differentiated strategy that women use in developing workplace contacts is to decrease the degree of multiplexity of women's social networks relative to men's (Ibarra, 1992). The findings in support of this argument were mixed; while unexpectedly, men and women had a similar overall number of multiplex ties, the results indicated that homophily was highly correlated with multiplexity for women, but not for men. In other words, women's multiplex relationships were generally homophilous, suggesting that once again, women may be at a disadvantage in forming strong multiplex relationships with the highest status (i.e. male) individuals in the organization. Further, common sense suggests individuals would be more likely to use their own social capital to assist a person with whom they have a multi-faceted relationship (i.e. a friend as well as a colleague) than someone with whom they only have a single relationship. Thus, women's lack of multiplex relationships with men may once again work to disadvantage them with respect to developing important high-status sponsors and ultimately, to developing the credibility necessary for advancement to the executive suite.

\section{Range}

Range refers to the breadth and diversity of ties within a network, and has been measured in several ways, including the number of contacts within a network, the diversity of types of contacts within a network, and the degree to which ties are situated within or across organizational workgroups. Diversity can be based upon a wide variety of attributes including the nature of the relationship (kin, coworker, friend, etc.), the ascribed attributes of the contact (gender, race, age, etc.), the organizational membership of the contact, or the status of the contact. A broad range of network ties, comprised of both strong and weak relationships with a diverse group of individuals has often been associated with access to greater instrumental resources (Campbell, 1988; Campbell et al., 1986; Marsden, 1987).

Several studies have explored whether the range of men's and women's networks differs.

Of note, Moore found that men's and women's network composition differed substantially, with men's networks including fewer kin ties and more non-kin ties such as coworkers, friends, and advisors (Moore, 1990). Women’s networks included more kin overall and more different types of kin ties, but fewer non-kin ties and types than men. However, after controlling for structural 
variables such as age, education, employment, marital status, and children, women's and men's networks were largely similar; the only significant remaining difference was that women continued to have more kin ties than men. These findings strongly support the conclusion that “most gender differences in networks were due to opportunities and constraints arising out of women's and men's different locations in the social structure’” (Moore, 1990, p. 734). Looking at network range exclusively in the workplace, another study found that highperforming women had wider ranging networks than high-performing men, including a substantial number of ties to higher or equal-status women across other organizations (Ibarra, 1997). Because of the constraints imposed by organizational demographics (i.e. few opportunities for highstatus intraorganizational ties to other women), women were forced to choose ' between dispersed homophilous contacts and within-group cross-gender ties;'” in this study, the most effective strategy appeared to be to cultivate wide-ranging homophilous ties and strong within-group cross-gender ties (Ibarra, 1997, p. 100).

There are several ways to interpret this strategy. First, it may be that women are aware of their "'legitimacy problem"' and thus recognize the need to develop strong relationships with high-status men within their organizations. Consequently, they actively attempt to augment their structurally prescribed instrumental relationships with such men with other types of ties. By focusing their resources internally, generating the credibility that emerges from strong relationships, and demonstrating indisputable levels of competence and ability (Pugh \& Wahrman, 1983), women may ultimately be successful in advancing within their organizations. However, outside their organizations where opportunities to display competence and to strengthen relationships are less frequent, these same women may be perceived as lower status and thus less likely to be sought out as network partners by high-status males. Additionally, both men and women are often careful of initiating cross-gender relationships outside the context of work because of the potential of having their intentions misconstrued. In contrast, less encumbered are women's opportunities to forge relationships with same- and higher-status women with whom they come in contact in their extraorganizational interactions. Further, higher status women may seek to mentor and advise lower status women in other organizations with whom they come in contact. Differentially mentoring women within their own organizations might be perceived of as favoritism; however, across organizational lines it is less observable and subject to scrutiny. As a result of these numerous dynamics, women's wider-ranging network ties tend to be with other women.

An alternative, but not mutually exclusive interpretation is that women are status conscious in forming instrumental ties within organization, but in forming their expressive ties look for homophilous relationships wherever they can find them. Since there are simply fewer women proximally available with whom to form relationships, women's same-sex relationships are necessarily wider ranged. The result of either mechanism is that the broader range of high performing women's networks seems to serve them well, but the absence of wide-ranging and 
multiplex cross-gender ties may still limit their ability to generate credibility outside of their own organizations and gain consideration for external career advancement opportunities.

\section{Network Centrality}

Generally speaking, network centrality is a measure of the prominence or visibility of an individual actor within a network. Thus, an individual with "high centrality" is typically well integrated in the network with extensive access to other actors. There are a variety of types and specific measures of centrality: the number of direct ties that an individual has to others in the network ("degree centrality"); the extent to which an individual is close to others in the network (i.e. connected through short paths with very few links) ("closeness centrality"); the extent to which an individual acts as an intermediary in the network, linking other individuals who are not already connected to each other ( "betweenness centrality"); and the amount of information contained in all of the network paths to which an individual is connected ("information centrality") (Wasserman \& Faust, 1994). Despite the fairly common usage of these specific centrality measures, within the gender literature, the term "centrality" is often used quite broadly and vaguely as a general measure of the degree to which a group or individual is integrated within a network with access to the resources, status, power, and influence shown to be associated with centrality (Ibarra, 1992).

In 1979, Lincoln and Miller carried out one of the first studies to investigate the influence of ascribed attributes on network centrality (Lincoln \& Miller, 1979). The study measured path distance (the smallest number of links required to connect to individuals in a network), a typical measure of closeness centrality, for employees in five professional and semi-professional organizations and used this measure to determine the degree to which gender, race, education, and authority influenced network position. With very few exceptions across the organizations, the findings showed that these four attributes "operate on network structure by determining which persons will occupy central locations and which persons will find themselves at the margin of an organization's social system;” specifically, “white males with high education in formal positions of authority have high probabilities of occupying the most central locations in the network space”' (Lincoln \& Miller, 1979, p. 193). Consistent with these findings, a later study also using path distance as a measure of centrality found that while women were equally central in the organization overall, they were much less central in men's networks and the dominant power coalition in the firm (Brass, 1985). Further, both influence and promotion were strongly associated with access to these groups. As a result, within the organization, women were perceived as less influential and received fewer promotions than men.

In contrast, another empirical work has reported somewhat more complex findings around the effects of gender on network centrality. A study of social and work networks within six federally sponsored agencies found that gender and race were not meaningful predictors in

explaining network centrality (also measured using path distance) (Miller et al., 1981). However, an analysis of the interaction effects between gender and measures of achieved status such as 
authority (formal rank), education, and professional experience showed that women were much less able than men to translate investments in education, experience, or authority into a more central organizational position. Specifically, women's authority was associated with network centrality, but much less so than for men; education did not indicate any clear payoff for women; and experience was found to be “virtually irrelevant”' (Miller et al., 1981).

Ibarra reported similar results using a somewhat more sophisticated measure of centrality, aggregate prominence, which "indexes individual centrality as a function of the centrality of those to whom one is connected through direct and indirect links”' (Ibarra, 1992, p. 432). According to this formulation of centrality, an individual is considered to be more central when linked to other individuals with high centrality themselves. While the study findings indicated than men had higher network centrality than women, these differences were entirely explained by differences between men and women in rank, department, education, tenure with the organization, prestige of past work, and professional activity. However, in consistence with Miller et al. (1981), the findings also showed that women were less able to convert achieved rank and professional activity into network centrality. In other words, investments by women to achieve the typical bureaucratic symbols of success resulted in lower returns than the same investments by men.

One logical explanation of this finding is again, the aura of illegitimacy that hangs over the achieved successes of women in organizations and even more broadly, across society. Because women are perceived as less professionally credible than men, their accomplishments such as educational attainment, achieved rank, and experience on the job may be suspect and therefore, less likely to be translated into the status, power, and opportunities for advancement that come with being central to an organization. Thus, women may be caught in a Catch-22 where in order to be considered professionally credible, they must be highly accomplished, but in order for these accomplishments to be valued and recognized, they must first be considered credible. While no single factor will provide a solution to this conundrum, we argue that this pattern again suggests that women may particularly benefit from the endorsement of an organizationally central, high-status professional sponsor.

\section{Network Constraint}

Network constraint is an inverse measure of an individual's social capital (i.e. social capital increases as network constraint decreases) and is a function of the number of ties in a network (size), the degree to which the ties know each other (density), and the extent to which the contacts in a network are indirectly connected through a central individual (hierarchy) (Burt, 1998). As a network becomes smaller in size, more dense, and more hierarchical, constraint increases (and social capital decreases) as in each instance, the number of available contact alternatives decreases. This measure was developed and used by Burt (1998) to show that the association between having greater social capital and early promotion can operate very differently for men and women. Specifically, for men, network constraint was negatively 
correlated with early promotion while for women, the opposite pattern was seen; i.e. greater network constraint and lower social capital translated into earlier promotion, contrary to what might be expected.

To explain these unexpected findings, Burt first considered and rejected the notion that women are more successful with dense, clique networks. The data showed that women had larger networks and no more dense ones than men. Thus, Burt concluded that "women have no less access than men do to the information and control benefits of structural holes that advance men's careers. They differ in how the firm reacts to their access'’ (Burt, 1998, p. 19). Second, while both men and women exhibited homophily, this homophily did not cause women to have more constrained networks and early promotion was not related to a preference for networking with women. Finally, based on a comparison between two women with similar network constraint but very different promotion timing, Burt concluded that the observed pattern was due to women's lack of legitimacy in the organization. Because of this lack of legitimacy, women who built their own networks directly were much less successful than women who "borrowed"' social capital from a high-status organizational sponsor and thus had more hierarchical and constrained networks. This finding once again illustrates that the path of career advancement is somewhat different for women than that for men. While credibility and organizational sponsorship can be helpful to any executive, for women, these factors are not just helpful; instead, they are virtually requirements to success, the absence of which may prove to be substantial roadblocks to their upward career mobility.

\section{Conclusions and Further Implications for Future Research}

In this chapter, we sought to understand the ways in which the different social networks in which female and male candidates are embedded strengthens or undermines the credibility they accumulate and are able to leverage in their attempts to reach the executive suite. Existing literature provides us with a quite rich understanding of the ways in which the social networks of men and women differ with respect to qualities such as homophily, tie strength, multiplexity, range, centrality, and network constraint, and the ways in which those differences are detrimental to women's influence, status, access to information, likelihood of promotion and hire, and career mobility. It is also instructive in identifying some of the systematic barriers that women face in translating rational investments in themselves into tangible benefits. The more recent social network investigations are also prescriptive in highlighting the increased importance for women of strategically managing their social networks to garner sponsorship from key individuals who provide access to opportunities which they otherwise would not be able to avail themselves. To a lesser degree, existing research can inform our investigation of what societal and organizational factors cause these gender differences in social networks. Clearly, it indicates that the gender composition of the organization and the relative status of men and women in that organization 
should be significant factors. However, with respect to other potentially influential factors, the existing social networks literature is largely silent.

While the social networks research conducted to date has been invaluable, clearly additional work is needed to specifically investigate the role of sponsorship in hiring and promotion processes. We echo and extend Ibarra's (1993) call for research at multiple levels, including work to understand both the societal and organizational level antecedents of gender differences in social networks, identification of actual differences, and examination of the outcomes of such differences, specifically as they relate to executive advancement. Research on the antecedents of dissimilarity in the social networks of men and women should first be situated within the broader context of our society, in particular paying attention to our overall gender belief system, which conceptualizes women as lower status, less competent, less powerful, and generally less attractive as network contacts. Understanding how this gender system operates on organizations in general, as well as on the individuals, who make up those organizations, is a critical first step to embarking upon research investigating the organizational antecedents of gender differences in advancement. In other words, to correctly identify organizational influences, we must first understand how, why and when the broader system of gender beliefs is operating.

At the organizational level, research focused on understanding currently unexplored factors on the creation and maintenance of social networks such as the reliance of individuals and organizations on gender stereotypes; the relative turnover and mobility of men and women; the age, overall size, and growth of the organization; the gender of organizational leadership; the gendering of occupations within organizations; and the existence or absence of diversity or mentoring policies would likely provide a meaningful advance in our understanding of the processes that lead to the differential representation of women and men in the executive suites of organizations. At the individual level, we need research that investigates differences in men's and women's social networks over time. This work would allow us to understand issues such as how networks are created and subsequently decay over time, and how men's and women's relative mix of weak and strong ties influences the ability to maintain and leverage their networks over time. Also potentially fruitful would be research that explores whether men and women use dissimilar strategies for building and using their social networks and whether these strategies advantage men or women in their attempts for advancement. Finally, with a firmer grasp on the causes and realities of gender differences in social networks, the strategies for building, maintaining and using these networks, and the ways in which networks change over time, we must also take a more systematic and careful look at the consequences of any disparities on the gender-based demography of organizations.

We know that social networks matter. We also know that one of the most significant barriers to women's successful career progression is their exclusion from these systems of social interaction where who gets what - power, status, money, and influence - is so often decided. As we already discussed, over the last two decades a core group of researchers have advanced our 
understanding of how the social networks of men and women differ, and why we should care. However, if we desire to address these differences in an effort to create a more equitable representation of men and women in high-power organizational positions, we must better understand their causes, consequences, and the dynamic processes in between. We hope that a future program of research along the lines suggested above will prove to be a step toward extending our knowledge about the social networks of men and women, elucidating the processes by which “opportunity structures”' are created and destroyed, and equalizing the suitability and risk assessments that are so critical to generating greater equality in the representation of men and women at the helm of organizations (Cabrera \& Thomas-Hunt, 2006).

\section{Acknowledgement}

We would like to thank Shelley Correll for her helpful suggestions on earlier drafts of this chapter.

\section{References}

Barnes, J. (1954). Class and committees in a Norwegian island parish. Human Relations, 7, 3958.

Bartol, K. M. (1978). The sex structuring of organizations: A search for possible causes. Academy of Management Review, 3, 805-815.

Blau, P. M. (1977). Inequality and heterogeneity: A primitive theory of social structure. New York, NY: Free Press.

Brass, D. J. (1984). Being in the right place - a structural-analysis of individual influence in an organization. Administrative Science Quarterly, 29(4), 518-539.

Brass, D. J. (1985). Men’s and women’s networks - a study of interaction patterns and influence in an organization. Academy of Management Journal, 28(2), 327-343.

Burt, R. S. (1992). Structural holes: The social structure of competition. Cambridge, MA: Harvard University Press.

Burt, R. S. (1998). The gender of social capital. Rationality and Society, 10(1), 5-46.

Cabrera, S. F., \& Thomas-Hunt, M. C. (2006). Risky business: A theoretical framework for the 
advancement of executive women. Manuscript in preparation.

Campbell, K. E. (1988). Gender differences in job-related networks. Work and Occupations, 15(2), 179-200.

Campbell, K. E., Marsden, P. V., \& Hurlbert, J. S. (1986). Social resources and socioeconomicstatus. Social Networks, 8(1), 97-117.

Carli, L. L. (2001). Gender and social influence. Journal of Social Issues, 57(4), 725-741.

Carroll, G. R., \& Teo, A. C. (1996). On the social networks of managers. Academy of Management Journal, 39(2), 421-440.

Catalyst. (2006). 2005 Catalyst census of women corporate officers and top earners of the Fortune 500. New York, NY:

Catalyst. Corrigan, M. E. (2002). The American college president: 2002 edition. Washington: American Council on Education.

DeMatteo, J. S., Dobbins, G. H., Myers, S. D., \& Facteau, C. L. (1996). Evaluations of leadership in preferential and merit-based leader selection situations. Leadership Quarterly, 7(1), 41-62.

van Emmerik, I. J. H. (2006). Gender differences in the creation of different types of social capital: A multilevel study. Social Networks, 28(1), 24-37.

Fortune. (2006). Women CEOs for Fortune 500 companies. Retrieved August 30, 2006, from http://money.cnn.com/magazines/fortune/fortune500/womenceos/

Granovetter, M. S. (1973). Strength of weak ties. American Journal of Sociology, 78(6), 13601380.

Granovetter, M. S. (1974). Getting a job; a study of contacts and careers. Cambridge, MA: Harvard University Press.

Granovetter, M. S. (1982). The strength of weak ties: A network theory revisited. In: P. V. Marsden \& N. Lin (Eds), Social structure and network analysis (pp. 105-130). Beverly Hills, CA: Sage Publications. 
Hogue, M. B., Yoder, J. D., \& Ludwig, J. (2002). Increasing initial leadership effectiveness: Assisting both women and men. Sex Roles, 46(11-12), 377-384.

Hollander, E. (1992). The essential interdependence of leadership and followership. Current Directions in Psychological Science, 1, 71-75.

House, J. S., Landis, K. R., \& Umberson, D. (1988). Social relationships and health. Science, 241(4865), 540-545. Ibarra, H. (1992).

Homophily and differential returns - sex-differences in network structure and access in an advertising firm. Administrative Science Quarterly, 37(3), 422-447.

Ibarra, H. (1993). Personal networks of women and minorities in management - a Conceptual framework. Academy of Management Review, 18(1), 56-87.

Ibarra, H. (1997). Paving an alternative route: Gender differences in managerial networks. Social Psychology Quarterly, 60(1), 91-102.

Kanter, R. M. (1977). Men and women of the corporation. New York, NY: Basic Books.

Krackhardt, D. (1992). The strength of strong ties: The importance of philos in organizations. In: N. Nohria \& R. G. Eccles (Eds), Networks and organizations: Structure, form, and action. Boston, MA: Harvard Business School Press.

Kram, K. E. (1988). Mentoring at work: Developmental relationships in organizational life. Lanham, MD: University Press of America.

Lin, N., Ensel, W. M., \& Vaughn, J. C. (1981). Social resources and strength of ties - structural factors in occupational-status attainment. American Sociological Review, 46(4), 393403.

Lincoln, J. R., \& Miller, J. (1979). Work and friendship ties in organizations - comparative analysis of relational networks. Administrative Science Quarterly, 24(2), 181-199.

Marsden, P. V. (1987). Core discussion networks of Americans. American Sociological Review, 52(1), 122-131.

McPherson, J. M., \& Smith-Lovin, L. (1987). Homophily in voluntary organizations - status 
distance and the composition of face-to-face groups. American Sociological Review, 52(3), 370-379.

McPherson, J. M., Smith-Lovin, L., \& Cook, J. M. (2001). Birds of a feather: Homophily in social networks. Annual Review of Sociology, 27, 415-444.

Mehra, A., Kilduff, M., \& Brass, D. J. (1998). At the margins: A distinctiveness approach to the social identity and social networks of underrepresented groups. Academy of Management Journal, 41(4), 441-452.

Miller, J. (1986). Pathways in the workplace: The effects of gender and race on access to organizational resources. Cambridge [Cambridgeshire], NY: Cambridge University Press.

Miller, J., Labovitz, S., \& Fry, L. (1975). Inequities in organizational experiences of women and men. Social Forces, 54(2), 365-381.

Miller, J., Lincoln, J. R., \& Olson, J. (1981). Rationality and equity in professional networks gender and race as factors in the stratification of interorganizational systems. American Journal of Sociology, 87(2), 308-335.

Moen, P., Dempster-McClain, D., \& Williams, R. M. (1989). Social integration and longevity an event history analysis of women's roles and resilience. American Sociological Review, 54(4), 635-647.

Moore, G. (1990). Structural determinants of men’s and women’s personal networks. American Sociological Review, 55(5), 726-735.

Podolny, J. M., \& Baron, J. N. (1997). Resources and relationships: Social networks and mobility in the workplace. American Sociological Review, 62(5), 673-693.

Pugh, M. D., \& Wahrman, R. (1983). Neutralizing sexism in mixed-sex groups - do women have to be better than men? American Journal of Sociology, 88(4), 746-762.

Ridgeway, C. L. (2001). Gender, status, and leadership. Journal of Social Issues, 57(4), 637-655.

Rutgers University, Eagleton Institute of Politics, Center for American Women and Politics. (2006). Facts on women candidates and elected officials. Retrieved August 26, 2006, from http://www.cawp.rutgers.edu/Facts.html\#elective 
Smith-Lovin, L., \& McPherson, J. M. (1992). You are who you know: A network approach to gender. In: P. England (Ed.), Theory on gender/feminism on theory (pp. 223251). New York, NY: Aldine.

South, S. J., Bonjean, C. M., Markham, W. T., \& Corder, J. (1982). Social-structure and intergroup interaction - men and women of the federal bureaucracy. American Sociological Review, 47(5), 587-599.

Steinpreis, R. E., Anders, K. A., \& Ritzke, D. (1999). The impact of gender on the review of the curricula vitae of job applicants and tenure candidates: A national empirical study. Sex Roles, 41(7-8), 509-528.

U.S. Census Bureau, Population Division. (2006). Annual estimates of the population by sex and five-year age groups for the United States: April 1, 2000 to July 1, 2005 (NCEST2005-01). Retrieved August 15, 2006, from http://www.census.gov/popest/ national/asrh/NC-EST2005/NC-EST2005-01.xls

Valian, V. (1998). Why so slow? The advancement of women. Cambridge, MA: MIT Press.

Wasserman, S., \& Faust, K. (1994). Social network analysis: Methods and applications. Cambridge, NY: Cambridge University Press.

Watts, D. J. (2003). Six degrees: The science of a connected age (1st ed.). New York, NY: Norton.

Yoder, J. D. (2001). Making leadership work more effectively for women. Journal of Social Issues, 57(4), 815-828.

Yoder, J. D., Schleicher, T. L., \& McDonald, T. W. (1998). Empowering token women leaders - the importance of organizationally legitimated credibility. Psychology of Women Quarterly, 22(2), 209-222. 